\title{
Clausal juxtaposition and subordination: New light from Otomi*
}

\author{
Enrique L. Palancar \\ Surrey Morphology Group \\ University of Surrey \\ To appear in Volker Gast and Holger Diesel (eds.) \\ Clause Combining in Cross-linguistic perspective \\ Berlin: Mouton de Gruyter
}

\section{Introduction}

In this paper, I argue that in some languages clausal juxtaposition can be used not only as a mechanism of semantic or pragmatic subordination, but also as as a device signaling syntactic subordination. This implies that the presence of clausal juxtaposition in the discourse of a given language does not necessarily imply the absence of the typical morphosyntactic hallmarks that characterize dependent clauses formally in other languages, especially if the relevant languages use juxtaposition as a typical clause combining device to encode semantically dependent events. In other words, I argue that it is important to keep apart the presence or absence of (i) syntactic dependency and (ii) markers of subordination (cf. Lehmann 1988). I illustrate this claim with data from a specific grammatical construction in Northern Otomi (Oto-Pamean, Oto-Manguean) from the variety of San Ildefonso Tultepec, which involves a juxtaposed dependent clause with a number of (morpho)syntactic properties commonly associated with subordination, in particular 'cross-clausal dependencies' as described by Gast \& Diessel (this volume), and the prosodic realization of the clauses concerned in a single intonation contour.

\subsection{Clausal juxtaposition: Parataxis and hypotaxis}

Clausal juxtaposition is traditionally taken to be a type of clause-combining strategy used to encode paratactic relations among clauses. In this function, clausal juxtaposition is rather common cross-linguistically. An English example is given in (1), where the two clauses involved are conveyed to be textually related in some way (Quirk et al. 1985: 1472).

\section{(1) He ate too much for dinner. He was ill the next day.}

In examples like (1), it is essential to keep two distinct phenomena apart which are often erroneously equated: (i) a type of a clause linkage mechanism and (ii) a type of a linking relation. The linkage mechanism used in (1) is that of "clausal juxtaposition". This term implies that two (or more) clauses are chained by just placing one after the other without using an overt conjunction. The type of linking relation that the two clauses in (1) display is that of "parataxis", traditionally defined as "the linking of elements of equal status" (Halliday 1985: 198). In (1) we have two matrix clauses of equal status.

Juxtaposing two clauses as a linking device naturally implies that there is no formal means indicating what semantic relation holds between them, but for examples like (1), Quirk et al. (1985) point out that the mere fact of using juxtaposition "raises the expectation that the second 
utterance [He was ill the next day] followed the first [He ate too much for dinner] as an iconic representation of being sequential in time or consequential in reasoning” (Quirk et al.: 1472). ${ }^{1}$ In other words, in English examples like (1) clausal juxtaposition serves as a linguistic icon of notions such as sequence and/or consequence, which are the quintessential conceptual notions associated with sentential conjunction.

As an alternative to juxtaposition, the use of coordinating conjunctions (and, but, or, etc.) is yet another way in which sentential conjunction can be encoded, as for example in (2) (adapted from Quirk et al. 1985: 1472).

\section{(2) [He ate too much for dinner] and [he was ill the next day].}

Coordinative constructions with conjunctions like and can also express sequence or consequence, but are regarded by many as imposing asymmetry on the conjuncts - beginning with Ross (1967), Schmerling (1975), Haiman (1985), Lakoff (1986), Deane (1992), and Johannessen (1998) - for example in the sense that the order of conjuncts cannot be reversed without affecting the meaning of the entire sentence. As both structures in (1) and (2) express semantic coordination, the coordinating construction in (2) is often regarded as "syndetic coordination", while the clausal juxtaposition linking strategy in (1) is commonly treated as "asyndetic coordination”.

Haiman (1985) provides various examples of languages which make productive use of both asyndetic and syndetic coordinating structures. In all such cases, the asyndetic construction conveys a closer conceptual distance between the events involved, presumably as a result of iconic motivation. This may be illustrated with the contrast between (3a) and (3b) from Fe?fe? Bamileke, a Bantu language (Hyman 1971, apud Haiman 1985: 113, translation and brackets mine). ${ }^{2}$

\section{(3) a. à kà gén ntēe [njwēn lwà?] he PST go market buy yams \\ 'He went to the market and bought yams.' \\ b. à kà gén ntēe [n̄i njwēn lwà? $]$ he PST go market and buy yams 'He went to the market and bought yams.'}

According to Hyman (1971: $43 \mathrm{fn}$ ), example (3a) "definitely implies that yams were bought at the market", whereas in (3b), the use of the conjunction disassociates the conjuncts, so that the second event is interpreted as having taken place at a later time and place.

While semantic coordination and parataxis could in principle be taken to be similar concepts at the semantic level, the literature also commonly treats the concepts of parataxis and clausal juxtaposition as being synonymous. This may be seen, for example, in Bowern (2008: 171) and in Cosme (2006: 74), among many others, including influential publications such as Noonan (1985, 2006), Thompson and Longacre (1985), Longacre (1985), and Thompson et al. (2007). 
In this contribution, I intend to show that clausal juxtaposition, despite its common paratactic function, can also be used to encode hypotactic relations, even in cases of highly integrated subordinate structures. I illustrate this claim in Otomi, a Mesoamerican, Oto-Manguean language family spoken in Central Mexico, in which such a strategy is extensively employed, and for this purpose I will use data from Northern Otomi, more specifically from the variety of San Ildefonso Tultepec.

\subsection{Distinguishing parataxis and hypotaxis}

The common contention that juxtaposition equals parataxis can be illustrated with the chapter on subordination written by Aarts (2006) for The Encyclopedia of Language and Linguistics (second edition). Aarts (2006: 252) claims that "[s]ubordination is a matter of degree", and referring to structures like in (1), he explicitly states that "clauses that are merely juxtaposed are paratactically linked”. The particular example under discussion is given in (4), about which the author rightly says: "Although there is an obvious semantic (causal) link between the first and second sentences in this example and co-reference is established through the use of the pronoun he, which may (but need not) refer back to Tim, grammatically neither sentence is subordinate to the other."

\section{(4) Tim fell. He broke his arm.}

Note that what is at issue in (4) is not that this example is an instance of subordination - which it is not - but that the use of clausal juxtaposition should not be taken to be the same thing as parataxis. Not even in languages like English are such categories always clearly associated. For example, Culicover and Jackendoff (1997) argue in favour of an analysis that regards syndetic coordinating structures like those in (5) as instances of semantic subordination, despite the typically paratactic function of such constructions, as in examples like (2) above.

(5) a. One more can of beer and I'm leaving.

b. You drink another can of beer and I'm leaving.

Similarly, the construction in (6) - an instance of clausal juxtaposition - is also regarded as involving semantic subordination by Hoeksema and Napoli (1993) - again, in contrast to typical paratactic examples like (1).

\section{(6) I fainted, the sun was so hot.}

Prosody is one the most crucial features leading to a subordinate interpretation of examples like (6). Based on data from an experimental study carried out on English native speakers, Hoeksema and Napoli (1993) claim that the clauses in (6) are uttered within a single intonation contour. As we will see in Section 2.2, prosody is an important criterion that can be used to identify subordination when clausal juxtaposition is involved. The structure in (6) contrasts with the one given in (7), where the second clause is conventionally regarded as being syntactically subordinated.

(7) The sun was so hot (that) I fainted. 
In this respect, Hoeksema and Napoli (1993) argue that the structure in (6) is located at an intermediate level of syntactic dependency, somewhere between the structure in (1), which conveys semantic coordination of the asyndetic type, and the structure in (6), which is clearly subordinative. ${ }^{3}$ This problem has been identified by Givón (1990: 826):

[T]he absolute distinction between subordinate ('dependent') and coordinate ('independent') clauses works only within rigidly prescribed typological bounds; and even there only with rigid pre-selection of the facts. Both its sharp distinction and its utility dissipates rapidly when one considers a broader typological sample, and analyses a wider range of functional and grammatical facts. In particular, a careful parallel analysis of the structural facts of clause integration and the functional facts of event integration reveals that in many languages, the sharp binary distinction between subordination and coordination is a gross over-simplification of the facts.

In examples (5) and (6), clause-combining strategies which are typically associated with parataxis can be regarded as encoding semantic subordination, even in English. Semantic subordination, as conceived of by Culicover and Jackendoff (1997), refers to the semantic dependence between two clauses which is not (necessarily) realized formally in the typical syntactic terms that characterize other, more conventional hypotactic structures. In view of such cases, and in order to accommodate a wider range of structures which do not always show the same formal properties, Cristofaro (2003: 2) takes a functional typological approach to subordination as a grammatical phenomenon, providing the following definition: “(A) particular way to construe the cognitive relation between two events, such that one of them (which will be called the dependent event) lacks autonomous profile, and is construed in the perspective of the other event (which will be called the main event).”

This definition implies a notion of subordination that is independent of the way in which clause linkage is realized across languages. Such a definition allows Cristofaro to include languages which make extensive use of clausal juxtaposition to encode dependent events, such as Mandarin Chinese. In this new light, clausal juxtaposition is regarded as a possible strategy to encode dependent clauses. The claim may be illustrated with example (8) from Mandarin Chinese (Li and Thompson 1973: 98).

\section{(8) nǐ guì-xialai [qiú Zháng-san] \\ you kneel.down beg Zhang-san \\ 'You knelt down in order to beg Zhang-san.'}

Example (8) instantiates a dependent purpose clause in Chinese, despite involving clausal juxtaposition, because "this is the way Mandarin expresses the conceptual situation associated with purpose clauses in other languages” (Cristofaro 2003: 2).

Nevertheless, the relation between clausal juxtaposition and subordination is still taken to work at a semantic or functional level only, but not at a syntactic level. Consider for this purpose Cristofaro's (2005: 506) own position, also in Cristofaro (2003: 98): “[B]egging Zhang-san is the goal of the person's kneeling, but the relevant clause does not show any of the morphosyntactic hallmarks that differentiate purpose clauses from main clauses in other languages." It is the purpose of this paper to show that clausal juxtaposition can equally be used as a mechanism of 
syntactic (rather than just semantic) subordination. To do so, in the next section I introduce the phenomenon in question in Otomi.

\subsection{Clausal juxtaposition in Otomi}

Otomi is a Mesoamerican language family of the Oto-Manguean stock which comprises about six to seven different languages. All Otomi languages have juxtaposed dependent clauses which may express purpose as in (9a) or may serve as clausal complements of specific matrix verbs, as in (9b). ${ }^{4}$ The examples I used in this paper to illustrate the phenomenon come from Northern Otomi, more specifically from the variety spoken in San Ildefonso Tultepec. ${ }^{5}$
a. 'ně $d a=h<\tilde{n}\rangle \check{o} t s '-i$
$[d a=m \underline{a}=p y a ́$ ]

and 3.PRES.IRR $=\langle$ SS $\rangle$ take[3OBJ]-F 3.PRES.IRR=SS/sell[3OBJ]=now

'And they took them (the tortillas) to sell them.' (Txt)
b. $d a^{\prime}=j w a ́=h e ́ \quad[d a ́=n \ddot{e}=h e ́]$
1.PST=finish.AS=PL.EXCL 1.PST=dance. $. \mathrm{AS}=\mathrm{PL} . \mathrm{EXCL}$
'We finished dancing.' (Txt)

The juxtaposed dependent clauses in (9) are syntactically reduced and are functionally (more or less) equivalent to typical infinitival clauses in Indo-European languages. The phenomenon under study in this paper appears to be a typological feature of Oto-Manguean, as similar structures have been reported in other groups, such as Trique (Longacre 1966) and Chatino (Pride 1965).

The present paper is structured as follows. In the next section, I introduce the grammatical construction instantiated in (9) in more detail, focusing on its prosody. In Section 3, I present a detailed analysis of the various grammatical properties that characterize the dependent juxtaposed clause type under consideration as a 'deranked' structure, namely: it exhibits tense/aspect/mood (TAM) restrictions, it features a rather reduced syntactic structure, and it shows inherent control. In order to illustrate the various properties more clearly, I compare this clause type with other dependent clauses in Otomi which are headed by conjunctions, such as other types of purpose clauses and complement clauses. In Section 4, a number of additional morphosyntactic characteristics are presented which involve the relation between the main and the dependent clause, and which suggest that the construction at hand shows a high degree of syntactic integration. This can be seen in the marking of plural subjects and in the morphological adjustment of the verb in the main clause. In Section 6, I summarize the proposal and revisit the relation between clausal juxtaposition and the parataxis/hypotaxis distinction.

\section{The purposive juxtaposed construction in Otomi}

\subsection{Syndetic and asyndetic purpose clauses}

Otomi is a Mesoamerican language family spoken in Central Mexico which pertains to the OtoPamean subgroup of Oto-Manguean. The analysis I present here is based on first-hand textual data from the Otomi language spoken in the village of San Ildefonso Tultepec (SIT), in the State of Querétaro, but the phenomenon under study is a family-trait, and earlier descriptions of the phenomenon have been provided for other Otomi languages, e.g. for Mezquital Otomi in Lanier 
(1968) and for Mexico State Otomi in Bartholomew (1973). Details of distribution within the family remain poorly understood, however. Typologically, Otomi languages are nominativeaccusative head-marking languages with complex synthetic morphology and extensive use of clitics.

A purpose construction like in English $I$ went downtown to see the movies is defined by Cristofaro (2005: 506) as " [ ... ] one encoding a particular relation between events. This relation is such that one of the linked events (the one coded by the main clause, or the main event) is performed with the goal of obtaining the realization of another one (the one coded by the purpose clause, or the dependent event)." In SIT Otomi, purpose semantics may be encoded by means of two types of subordinating constructions, which in many situations are freely interchangeable (see Section 3 for a number of restrictions):

- One construction which involves a main clause and a dependent finite clause expressing purpose introduced by the conjunction $p a ́$ - a loan from Spanish pa(ra) - as shown in (10).

$$
\begin{aligned}
& \text { hö, } \left.\quad d a^{\prime}=h \ddot{u} d-i \quad \text { [pá } \quad d a^{\prime}=k^{\prime} \operatorname{oot}^{\prime}{ }^{\prime}-i\right] \\
& \text { yes 1.PST=sit-F PURP 1.PST=look.at[3OBJ]-F } \\
& \text { 'Yes, I sat down to look at it.' (Txt) }
\end{aligned}
$$

- Another construction which consists of a main clause and a juxtaposed dependent clause that follows it. I will refer to this construction as the "juxtaposed construction". In this construction, the dependent clause is taken to be "finite" in a traditional sense, as it is marked for TAM and for subject agreement, but as it will be shown in Section 3.3, the juxtaposed clause is also structurally deranked, and should be considered as less finite than the dependent clause in (10). An example is given in (11) from the same text as (10).

$$
\begin{aligned}
& d \dot{a}={ }^{\prime} b \underline{a} t^{\prime}-i \quad\left[d a ́=h a n d-a=n \check{o}=r \quad f o^{\prime h} k o\right] \\
& \text { 1.PST=turn.around-F 1.PST=look.at[3OBJ]-B=DEF.SG=SG bulb } \\
& \text { 'I turned around to look at the bulb.' (Lit. I turned I looked at the bulb.') [18/10-11] }
\end{aligned}
$$

When considered in isolation, the finite juxtaposed clause in (10a) could be taken at a surface level at least to be just like the finite clause in (10b), the only difference being that there is no subordinator. In this sense, I will also refer to this type of clause as the "asyndetic" dependent clause, whereas the first one will be called "syndetic". I show in the next sections, however, that these two examples instantiate two very different subordinate constructions.

\subsection{Prosodic properties of purpose adjunct clauses}

One fundamental difference between syndetic and asyndetic purpose clauses concerns their prosodic structures. The dependent clause in (11) above is embedded in the overall phonological structure of the main clause. This motivates the prosodic realization of the dependent clause within the intonational contour of the main clause (Nespor and Vogel 1986). Consequently, no pause - indicated by the symbol "\#” — can occur at the juncture between the clauses. This may be seen in the contrast between (12a) and (12b); the latter example not allowing the purposive interpretation of (12a). 
(12)

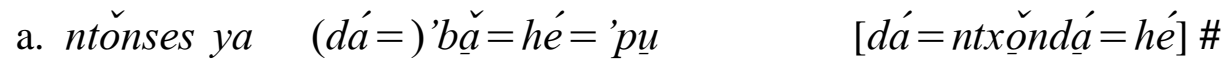
then $\mathrm{P}$ 1.PST=stand.AS=PL.EXCL=there 1.PST=have.a.look=PL.EXCL
'We then stood up there to have a look.' (Txt)

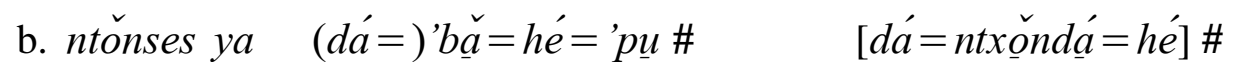
then $\mathrm{P} \quad 1 . \mathrm{PST}=$ stand.AS=PL.EXCL=there 1.PST=have.a.look=PL.EXCL
*Intended reading: 'We then stood up there to have a look.'
Meaning conveyed: 'We then stood up there (and) had a look.'

While the pause is not possible at clausal juncture, it may freely occur in the middle of either clause, as shown in (13), where the speaker is mentally searching for phrasal and lexical options within the dependent clause.

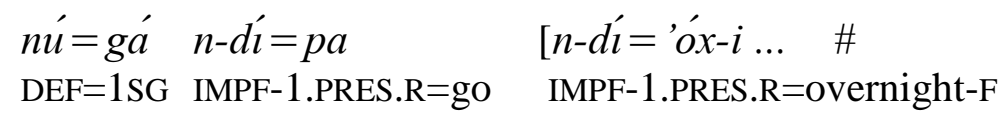

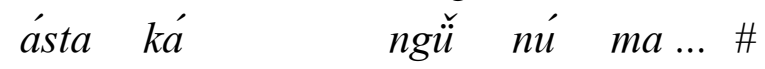

$$
\begin{aligned}
& \text { up.to P.LOC.3POSS house DEF 1POSS } \\
& \text { nó ma kómpá 'ně má n'à ntxütsi] \# } \\
& \text { DEF.SG 1POSS friend and other one girl }
\end{aligned}
$$

'I used to go to spend the night ... at the house of my ... of a friend of mine and another girl's.' (Txt)

In contrast to the juxtaposed construction in (11), (12a) and (13), the syndetic purpose clause headed by $p a ́$ in (10) forms an independent phonological phrase, and a pause may freely occur at the juncture between the clauses - in particular, after the main clause, as shown in (14). This is also true of all other syndetic dependent clauses in Otomi, as in example (15), a complement clause headed by the complementizer $g e$.

(14) má n'à_gi bá=pěng-i (\#)

other one_time 3.HITHER.PST=return-F

$$
\begin{array}{ll}
\text { [pá } \quad b i=\tilde{n} \ddot{u} n g-a=m a ́ & \left.n ’ \check{a} \_g i\right] \# \\
\text { PURP } & \text { 3.PST=have.a.meal.AS-B=other } \\
\text { 'He returned again to eat again.' (Txt) }
\end{array}
$$

$$
\begin{aligned}
& \text { (15) kábu ya } g a=x i-p=k a ́ \quad \text { ar txitá (\#) } \\
& \text { after.all } \mathrm{P} \text { 1.PRES.IRR=say-3DAT=1SG.EMPH SG deity }
\end{aligned}
$$

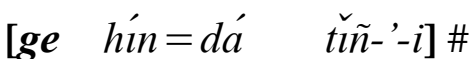

$$
\begin{aligned}
& \text { C NEG=1.PST find.A-2OBJ-F } \\
& \text { 'After all, I will tell God that I didn’t find you.' (Txt) }
\end{aligned}
$$

The fact that juxtaposed dependent clauses fall under a single intonation contour together with the main clause indicates that the juxtaposed construction is a complex clause. Using prosodic criteria to identify complex clauses is common (for example, Givón 2009: Chapter 4), and may 
ultimately be motivated by an iconic principle involving conceptual distance and formal marking, as proposed in Haiman (1985).

In contrast, if clausal juxtaposition is used to encode paratactic relations, a pause may freely occur at the juncture between the clauses. This may be seen in (16), which illustrates a chain of clauses standing in a paratactic relation to each other, thus expressing a sequence of events.

$$
\begin{aligned}
& \text { [bi=n-küh=wí] \# } \\
& \text { 3.PST=MIDD-chase.AS=DU } \\
& \text { 'It (the snake) chased her,' } \\
& \text { [bi=mïh-i]]\# } \\
& \text { 3.PST=catch[3OBJ]-F } \\
& \text { 'caught her,' } \\
& \text { [bi=xót'-e }] \text { \# } \\
& \text { 3.PST=coil.around[3OBJ]-F } \\
& \text { '(and) coiled around her.' (Txt) }
\end{aligned}
$$

Accordingly, a juxtaposed clause in Otomi discourse may either be subordinated to another clause - as in (11) - or it may be paratactically linked to a previous clause - as in (17). Using juxtaposition necessarily implies that the type of relation that a given clause bears to a preceding clause is not explicitly marked, prompting the hearer to rely on other cues, a crucial one being intonation. For example, in the textual string in (17), we have two different instances of juxtaposed clauses:

$$
\begin{aligned}
& \text { a. }\left[b i=g \underline{u}^{h} k-a=n \check{o}=r \quad k a ́ h a ́\right. \\
& \text { 3.PST=SS/extract[3OBJ]-B=DEF.SG=SG box } \\
& \text { há } \quad m i=k \breve{u}=r \quad \text { bojö] \# } \\
& \text { where 3.IMPF. } \mathrm{R}=\text { for.a.mass.to.be.located }=\mathrm{SG} \text { money } \\
& \text { 'They got the box out where the money was.' }
\end{aligned}
$$

The juxtaposed clause in (17b) is paratactically linked to (17a). The clause in (17d) is an asyndetic dependent clause expressing purpose and is embedded within (17c). If the speaker had wanted to present the event involving the counting of the money in (17b) as a goal event, he would have included the clause bi mede 'he counted it' within the same intonational phrase as (17a). However, as (17a) is phonologically heavy, opting for a syndetic purpose clause would be a better option, like in (18). 
(18)
a. $b i=g \underline{u}^{h} k-a=n \check{c}=r \quad k a ́ h a ́$
3.PST=SS/get.out[3OBJ]-B=DEF.SG=SG box
ha $\quad m \dot{\imath}=k \grave{u}=r$
where 3.IMPF. $\mathrm{R}=$ for.a.mass.to.be.located $=\mathrm{SG}$
bojö (\#)
money

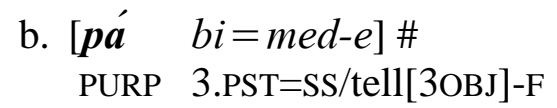
'They got the box out where the money was to count it.'

Likewise, the juxtaposed clause $b i$ 'umbi 'he gave it to him' in (17d) is construed as a purpose clause by the hearer because of its prosodic embedding. A prosodic structure as in (19) would have rendered a paratactic alignment.

$$
\begin{aligned}
& \text { ['ně } \quad b i=h e^{h} k-a=m a ́ d \check{e}=t h o ́ \text { ] \# } \\
& \text { and } 3 . \mathrm{PST}=\text { divide[3OBJ]-B=half }=\mathrm{DEL} \\
& \text { [bi= 'um- } b-i] \text { \# } \\
& \text { 3.PST=give.to.3.AS-3DAT-F }
\end{aligned}
$$

'And he divided it up (and) he gave it to him.'

These facts seem to imply that two sentences considered in isolation could in principle be taken to be ambiguous at a surface level if prosody were not taken into account. Such a point of view, nevertheless, may risk oversimplifying the facts by taking for granted that the internal structure of these apparently ambiguous sentences is the same. In the rest of the paper, I aim to show that the dependent juxtaposed clause in Otomi in (17d) is a deranked structure which is functionally equivalent to other, more typical, deranked structures like infinitives or gerundives in other languages. This clause is different from infinitives and gerundives in that it is marked for TAM and subject agreement, and in that it emerged from the truncation of a full-fledged clause and has never had the external syntax of an NP. While the case is made with data from Otomi, a similar syntactic behaviour is expected in other languages where clausal juxtaposition is used to encode semantic dependency.

Note that, while a purposive interpretation is the most common reading rendered by the juxtaposed adjunct clause in (17d), a simultaneous manner interpretation is at times possible, as for example in (20). ${ }^{6}$

$$
\begin{aligned}
& \text { a. } m \dot{\imath}=h \ddot{u}^{h}={ }^{\prime} p \underline{u} \quad\left[m \dot{\imath}=k a ̈ x x t^{\prime}-i\right] \\
& \text { 3.IMPF. } \mathrm{R}=\text { sit. } . \mathrm{S}=\text { there } 3 . \mathrm{IMPF} . \mathrm{R}=\text { massage[3OBJ]-F }
\end{aligned}
$$

$\begin{array}{llll}\text { b. } i & y a & n \check{=}=r & n d \underline{a} \\ \text { and } & \mathrm{P} & \text { DEF.SG=SG } & \text { man }\end{array}$

$$
\text { sigi } b i={ }^{\prime} b \underline{a}=n \underline{u} \quad\left[b{ }_{i}^{\prime}=\text { tó }^{\prime} m-i\right]={ }^{\prime} n a
$$

AUX 3.PST=stand.AS=there 3.THITHER=wait[3OBJ]-F=QUOT

'And they say that the man kept on standing there waiting for her.' (Txt) 
In examples like (20), the preferred reading is one of simultaneity of two events. Such a reading is obtained when the main clause expresses an aspectually imperfective event. The imperfective aspect conveys a stable state of affairs which takes place without a significant change in the dynamism. In such cases, the clause does not favour an interpretation of the event as being performed with the goal of realizing the dependent event. There are also cases with an ambiguous reading between purpose and manner, as for example in (21).

$$
\begin{aligned}
& d a^{\prime}=y^{\prime}=h e ́=' p \underline{u} \quad k a^{\prime} \quad t a i \\
& \text { 1.PST=walk=PL.EXCL=there LOC.P market } \\
& {[\text { dá }=\text { ntxōnda }=\text { hé }} \\
& \text { 1.PSD=have.a.look[3OBJ]=PL.EXCL } \\
& \text { té má } \varnothing \text { găthó } \varnothing=j a=' p u] \\
& \text { something other REL all 3.PRES.R=exist=there } \\
& \text { 'We walked around the market to have/having a look at all that was there.' (Txt) }
\end{aligned}
$$

The relative freedom in the interpretation of the type of adverbial semantics expressed by the dependent clause is a consequence of clausal juxtaposition as a linking mechanism, given that there is no overt marker to favour one interpretation over another. In this respect, the semantic relation between the main and the dependent clause very much relies on the pragmatic interpretation between the two events involved based on conversational implicatures. ${ }^{7}$

\section{Morphosyntactic properties of the juxtaposed construction}

The construction illustrated in Section 2 shows a high degree of syntactic integration between the main and the dependent juxtaposed clause. This can be seen not only in prosodic terms, but also in other properties which will be presented in this section.

\subsection{Marking of TAM}

In Otomi languages, TAM is encoded by paradigms of verbal clitics which also cross-reference the person of the subject. Table 1 surveys common tenses and moods in SIT Otomi:

\begin{tabular}{lllll} 
Mood & Tense/Aspect & $1^{\text {st }}$ p. & $2^{\text {nd }}{ }^{\text {p. }}$ & $3^{\text {rd }} \mathrm{p}^{8}$ \\
\hline Realis & Present & dí & gí & $(\varnothing)$ \\
& Imperfect & ndí & ngí & mí \\
& Past & dá & gá & bi \\
& Hither Past & & & bá \\
& Perfect & xtá & xká & xi \\
& Plu-perfect & & & xki \\
\hline Irrealis & Present & ga & gi & da \\
& Immediative & ma $=$ ga & ma=gi & ma da \\
& Imperfect & nga & ngi & nda \\
& Perfect & xka & xki & xta \\
\hline
\end{tabular}

Table 1. Common TAM markers in SIT Otomi.

Examples of the present realis are given in (22) for all persons: 
(22)
a. $\boldsymbol{d}^{\prime}=t s \ddot{u}=g a^{\prime}$
1.PRES.R=get.scared $=1 \mathrm{EMPH}$
'I am scared.' (Txt)
b. $j a=\boldsymbol{g}^{\prime}={ }^{\prime} b \underline{u}^{h}=k w a$ LOC.ACT=2.PRES.R=live.AS=here
'You're indeed living here.' (Txt)
c. zǒng- $a=m a ́ \quad \quad n ' a ̈ a g i$
[3.PRES.R] weep.AS-B=other one_time
'She's weeping again.' (Txt)

The dependent clause in the juxtaposed construction has TAM encoding restrictions. It may appear in the irrealis mood, as shown in (23), or otherwise it copies the TAM-values of the main clause, as illustrated in (24) with present and perfect forms of the realis.

$$
\begin{aligned}
& b i=m a \quad n \check{a}=r \quad \text { 'béhñö } \\
& \text { 3.PST }=\text { SS/go DEF.SG }=\text { SG woman } \\
& {\left[\boldsymbol{m a}=\boldsymbol{d a}=h \check{o}=r \quad \text { déhe }={ }^{\prime} n a\right]} \\
& \text { IMM=3.PRES.IRR }=\text { bring }[3 \mathrm{OBJ}]=\mathrm{SG} \quad \text { water }=\mathrm{QUOT}
\end{aligned}
$$

$$
\begin{aligned}
& \text { a. PRES=[PRES] } \\
& \text { pe tó'be }=\boldsymbol{d} \boldsymbol{i} \quad \text { pa }\left[\boldsymbol{d}_{\boldsymbol{i}}=\text { zèngwa }\right] \\
& \text { but still=1.PRES.R go 1.PRES.R=visit[3OBJ] } \\
& \text { 'But I'm still going there to visit her.' (Txt) }
\end{aligned}
$$

b. PERF $=[$ PERF $]$

$$
\begin{aligned}
& \text { ya nó=r 'béhñö ya xi=náng-i n'l'tho } \\
& \mathrm{P} \text { DEF.SG.3POSS=SG woman P 3.PERF.R=get.up-F early } \\
& \text { [xi=n-kún-i] } \\
& \text { 3.PERF. } \mathrm{R}=\text { ANTIP-grind-F } \\
& \text { 'His wife has already got up early to grind corn.' (Txt) }
\end{aligned}
$$

The choice of TAM-value is semantically motivated when the dependent clause expresses purpose. When the irrealis is used, as in (23), the purpose event is presented as a potential event that has not yet happened, from the perspective of the temporal reference-point established in the main event. In contrast, when the TAM is copied, as in the examples in (24), the goal event in the purpose clause is regarded as factual, that is, it is conceived of as an attained goal -as having actually occurred after the main event. Consider example (25). Here, the act of sitting was performed prior to the act of seeing a given woman, and with the objective of obtaining the realization of that seeing event. The use of the past tense in the juxtaposed dependent clause moreover indicates that the man indeed saw the woman in question. ${ }^{9}$ 
(25) $\mathrm{PST}=[\mathrm{PST}]$

ntónse $\quad \boldsymbol{b i}=h\langle\tilde{n}) \ddot{u}^{h}={ }^{\prime} p \underline{u} \quad[\boldsymbol{b} \boldsymbol{i}=h\langle y\rangle$ and $-i]$

then $\quad$ 3.PST $=\langle$ SS $>$ sit.AS=there 3.PST $=\langle$ SS $\rangle$ see[3OBJ]-F

'He then sat down to see her (and he saw her).' (Txt)

If no irrealis tense is used - as in (23) - the copying of the TAM-features of the main clause is obligatory. This can be seen in (26), when compared to the ungrammaticality of the examples in (27).

(26)

$$
\begin{aligned}
& \mathrm{IMPF}=[\mathrm{IMPF}] \\
& \boldsymbol{m} \boldsymbol{\imath}=p a \quad\left[\boldsymbol{m} \boldsymbol{i}=k^{\prime} \ddot{o} n-i\right]={ }^{\prime} n a
\end{aligned}
$$

3.IMPF.R=go 3.IMPF. $\mathrm{R}=$ have.a.look.out-F=QUOT

'It's said that they were going there to have a quick look (and he had a look).' (Txt)
a. ${ }^{*} \mathrm{IMPF} \neq[\mathrm{PST}]$

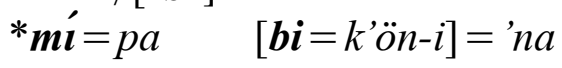
3.IMPF.R=go 3.PST=have.a.look.out-F=QUOT
Intended reading: like (26)
b. *PST $\neq[\mathrm{IMPF}]$
$* \boldsymbol{b i}=m a \quad\left[\boldsymbol{m} \boldsymbol{i}=k^{\prime} \ddot{o} n-i\right]={ }^{\prime} n a$
3.PST=SS/go 3.IMPF.R=have.a.look.out-F=QUOT
Intended reading: like (26)

Similarly, purpose clauses headed by the conjunction pá can also appear in the irrealis mood if the goal event is seen as potential, as for example in (28), or in any of the tenses of the realis mood if it is regarded as factual, like in (29).

$\begin{array}{ll}m i=h \check{x} x-a=r & \text { xóni } \text { kó déhe } \\ \text { 3.IMPF.R=take. } \mathrm{A}[\text { [ОBJ]-B=SG jug with water }\end{array}$

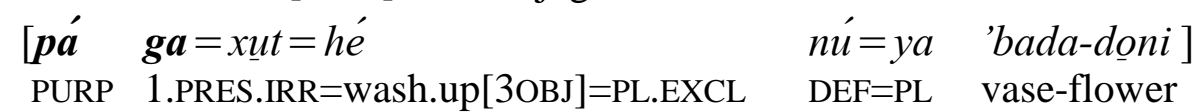

'She was taking a jug with water so that we could wash up the vases.' (Txt)

$\begin{array}{ll}b i={ }^{\prime}\langle y\rangle a m-b-a=b i=r & s \ddot{e} i \\ \text { 3.PST }=\langle\text { SS }>\text { extract.liquid.A-3DAT-B=3DAT=SG } & \text { agave.sap }\end{array}$

$\left[\begin{array}{ll}\boldsymbol{p a} & \boldsymbol{b} \boldsymbol{i}=z i]\end{array}\right.$

PURP 3.PST $=$ SS/ingest[3OBJ]

'They took some pulque from her in order to drink it (and they drank it). ${ }^{10}$ (Txt)

However, in contrast to the juxtaposed dependent clause, the TAM-features of the purpose clause headed by pá are not copied from the main clause, as is the case in any other dependent clause headed by a conjunction. This may be seen in the examples of (30) when compared with the ungrammaticality of (27) above. 
(30)

a. $\mathrm{IMPF} \neq[\mathrm{PST}]$

$$
\begin{aligned}
& \text { kó ya hé'mi mí=jǒ } \quad \text { mí=njanu } \\
& \text { with PL paper 3.IMPF.R=put.together[3ОBJ] 3.IMPF.R=be.like.that } \\
& \text { [pá } \left.\quad \boldsymbol{b i}=k w a^{\prime} t-i\right] \\
& \text { PURP 3.PST=put.away[3OBJ]-F }
\end{aligned}
$$

b. $\mathrm{PST} \neq[\mathrm{IMPF}]$

$$
\begin{aligned}
& b i=m a \quad \boldsymbol{b} \boldsymbol{a}=t \underline{u}=r \quad \text { male } \\
& \text { 3.PST=SS/go 3.HITHER.PST=reach.A.3POSS[3OBJ]=SG grandmother } \\
& \text { [pá } \quad \boldsymbol{m} \boldsymbol{\imath}=m-\underline{u} h=w i] \\
& \text { PURP 3.IMPF. } \mathrm{R}=\text { MIDD-live. } \mathrm{A}=\mathrm{DU} \\
& \text { 'They went to reach their grandmother to live with her.' (Txt) }
\end{aligned}
$$

\subsubsection{Verbs in the main clause and the TAM-features of the juxtaposed clause}

When the asyndetic dependent clause functions as a clausal adjunct, there is no lexical restriction as to which verb may occur in the main clause - provided, of course, that it is semantically compatible with the event described in the second clause. Therefore, we may have verbs in the main clause expressing transfer such as 'úni 'give' (cf. [31a]), or change of state as 'ıni 'spread' (cf. [31b]).
a. $b i={ }^{\prime} u m-b-i \quad[b i=z a]$
3.PST=give.to.3.A-3DAT-F 3.PST=SS/bite[3OBJ]
'He gave it to him to eat.' (Txt)
b. $d a=\stackrel{2}{\prime \prime} n-i \quad\left[d a='\left\langle y>o^{\prime} t^{\prime}-i\right]\right.$
3.PRES.IRR $=$ spread[3OBJ]-F PRES.IRR $=\langle$ SS $>$ get.dry[3OBJ $]-F$
'One spreads it (the corn) for it to dry.' (Txt)

Nevertheless, the most common main predicates in the construction are motion verbs. This is typologically expected, as pointed out by Cristofaro (2005), because the participant moving in the main event is identified with the actor of the goal event, and this identification is favoured by the cognitive presumption that people move with the volition and intention of doing other actions. The most frequent motion verbs entering in the juxtaposition construction of SIT Otomi are given in Table 2, together with a number of common verbs expressing change of posture: 


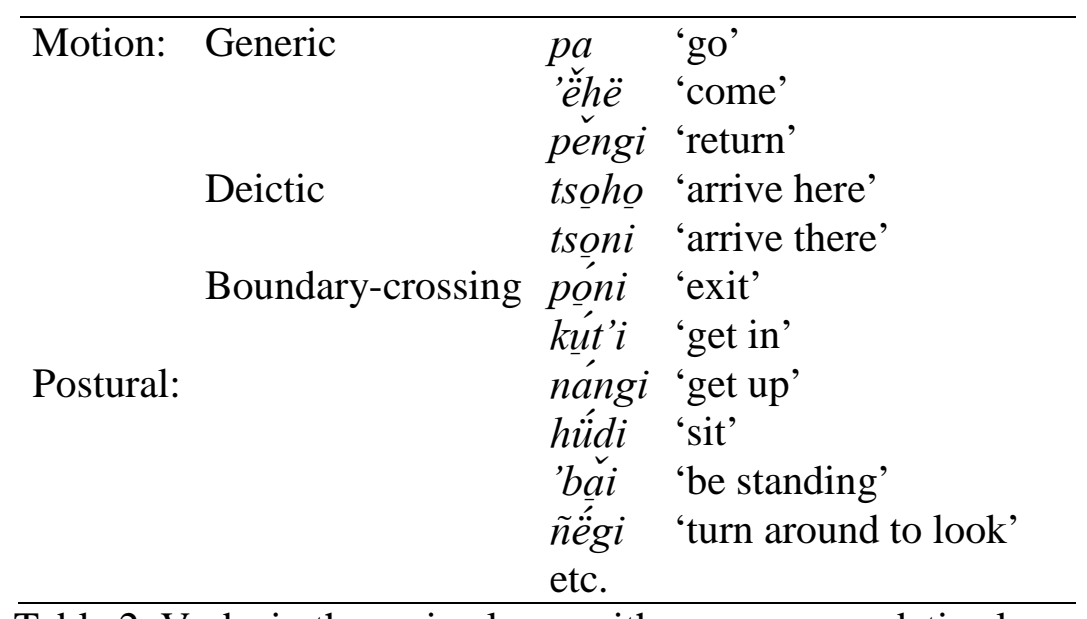

Table 2. Verbs in the main clause with purpose asyndetic clause

\subsubsection{Juxtaposed clauses in complement function}

As mentioned in Section 1.3, the juxtaposed dependent clause is also used in Otomi as a grammatical means to encode the clausal complements of specific matrix verbs (mainly desiderative, manipulative, modal, phasal, and a few others). In this way, the construction serves as a "complementation strategy" in the sense of Dixon (1995, 2006). Two examples are given in (32) with the matrix verbs $n e$ 'want' and ndui 'start'.
a. $y a$ hin $=d a ́$ ne $\quad\left[d a^{\prime}={ }^{\prime} b \underline{u}^{h}=' p u\right]$
$P \quad$ NEG=1.PST want[3OBJ] 1.PST=live.AS=there
'I didn't want to live there.' (Txt)

b. $b i=n d \underline{u}-i \quad[b i=\tilde{n} \underline{u} n-i]$

3.PST $=$ start-F 3. PST $=$ thunder-F

'It started thundering.' (Txt)

The matrix verbs most often found in this construction are given in Table 3. When functioning as a complement, the juxtaposed clause has the same syntactic properties as when it functions as an adjunct, but it shows further restrictions concerning the selection of TAM-values. These restrictions are indicated in the table. The verbs in Table 3 are also grouped according to their semantic classes. Note that the construction is typologically coherent with the proposal made by Cristofaro (2003), as the matrix verbs selecting a juxtaposed dependent clause are those which are expected to select a deranked or less complex clausal complement from a typological point of view. 


\begin{tabular}{|c|c|c|c|c|c|}
\hline & & & $\begin{array}{l}\text { Only } \\
\text { copy } \\
\text { of } \\
\text { TAM }\end{array}$ & $\begin{array}{l}\text { IRR possible in } \\
\text { imperfect and } \\
\text { negative; } \\
\text { otherwise a copy }\end{array}$ & $\begin{array}{l}\text { Only } \\
\text { IRR }\end{array}$ \\
\hline \multirow[t]{2}{*}{ Emotion: } & tsü (intr.) & 'be/get scared to do X' & $\sqrt{ }$ & & \\
\hline & kóstá (dat) & 'be difficult for one to do $\mathrm{X}$ ' & $\sqrt{ }$ & & \\
\hline \multirow[t]{2}{*}{ Cognition: } & pö́di (tr.) & 'know how to do X' & $\sqrt{ }$ & & \\
\hline & döhñi (intr.) & 'be/get lazy at doing $X$ ' & & & $\sqrt{ }$ \\
\hline \multirow[t]{3}{*}{ Desiderative: } & jáhni (intr.) & 'set at doing $X$ ' & $\sqrt{ }$ & & \\
\hline & ne (tr.) & 'want to do X' & & & $\sqrt{ }$ \\
\hline & gústá (intr.) & 'like to do X' & & & $\sqrt{ }$ \\
\hline \multirow[t]{3}{*}{ Manipulation: } & $j a ̂(d t r)$. & 'make/force sb. to do X' & $\sqrt{ }$ & & \\
\hline & 'befi (tr.) & 'command sb. to do X' & $\sqrt{?}$ & & \\
\hline & ${ }^{\prime}{ }^{h} t e$ (tr.) & 'obey sb. to do X' & $\sqrt{ }$ & & \\
\hline Causative: & hegi (tr.) & 'allow/let sb. do X' & $\sqrt{ }$ & $\sqrt{ }$ & \\
\hline \multirow[t]{3}{*}{ Modal: } & fats'i (tr.) & 'help sb. do X' & $\sqrt{ }$ & & \\
\hline & $t s \underline{a}(\operatorname{tr})$. & 'try to do $\mathrm{X}$ ' & $\sqrt{ }$ & & $\sqrt{ }$ \\
\hline & tsa (intr.) & 'be possible to do X' & & & $\sqrt{ }$ \\
\hline \multirow[t]{10}{*}{ Phasal: } & jáhni (intr.) & 'be fully engaged in doing $X$ ' & $\sqrt{ }$ & & \\
\hline & sigí (intr.) & 'continue doing $\mathrm{X}$ ' & $\sqrt{ }$ & & \\
\hline & thege (intr.) & 'affect completely by doing $\mathrm{X}$ ' & $\sqrt{ }$ & & \\
\hline & tége (tr.) & 'finish/consume sth. by doing $X$ ' & $\sqrt{ }$ & & \\
\hline & fúdi (intr.) & 'begin doing $X$ ' & $\sqrt{ }$ & & \\
\hline & ndui (intr.) & 'start doing X' & $\sqrt{ }$ & & \\
\hline & du'mi (tr.) & 'start doing X' & $\sqrt{ }$ & $\sqrt{ }$ & \\
\hline & hegi (tr.) & 'stop doing $X$ ' & $\sqrt{ }$ & $\sqrt{ }$ & \\
\hline & jwádi (lab.) & 'finish doing action $\mathrm{X}$ ' & $\sqrt{ }$ & $\sqrt{ }$ & \\
\hline & $j w a^{h} t i$ (lab.) & 'finish carrying out event $\mathrm{X}$ ' & $\sqrt{ }$ & $\sqrt{ }$ & \\
\hline
\end{tabular}

Table 3. Matrix verbs requiring a juxtaposed clausal complement.

\subsection{Negation}

Asyndetic dependent clauses cannot be morphosyntactically negated. When the main clause is negated, the scope of negation comprises the dependent clause. This can be seen in (33) with a purpose clause. ${ }^{1}$

$$
\begin{aligned}
& \text { him }=b i \quad m a \quad[b a ́=t s i-\text { the }=\text { 'yá }]=\text { 'na, } \\
& \text { NEG=3.PST SS/go } \quad \text { 3.HITHER.PST=ingest-water.AS=P=QUOT } \\
& b i=m a=\text { 'yá tá Ntai } \\
& \text { 3.PST=SS/go=P up.to Amealco }
\end{aligned}
$$

'They say he didn’t go to have a drink, he went to Amealco.' (Txt)

In example (33), the actor of the main event performs the action of going —although the main clause is negated - but not with the objective of having a drink, but of visiting a nearby town called Amealco. The marking of negation in (33), the procliticized morpheme him-, is syntactically associated with the main clause but has scope over the event in the dependent clause. Placing the negative marker in the juxtaposed clause renders the sentence ungrammatical, as shown in (34). 

* bi=ma $\quad[$ him $=b a ́ \quad$ tsi-the $]$
3.PST=SS/go NEG=3.HITHER.PST ingest-water.AS
Intended reading: 'He went away in order not to have a drink.'

In the intended reading of (34), the main event is performed in order to avoid the happening of the goal event. For such cases, speakers of SIT Otomi use a negated purpose clause headed by $p a$, as in (35):

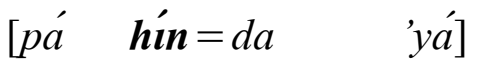

$$
\begin{aligned}
& \text { PURP NEG=PRES.IRR } \operatorname{rot}[3 \mathrm{OBJ}]
\end{aligned}
$$

b. $b i=z e^{e} m=y a \quad d o$

3.PST $=\mathrm{SS} /$ cover.up[3OBJ $]=\mathrm{PL} \quad$ stone

$$
\left.\begin{array}{llll}
{[p a ́} & h_{i}^{\prime} \boldsymbol{m}=b i \quad d \check{\imath} m-b-a=b i ́ & y a & m b o ́ h o
\end{array}\right]
$$

'They cover it (the money) up with stones so that the mestizos wouldn't find it on them.' (Txt)

When the dependent clause functions as a complement clause, the tight structural relation between the main predicate and its clausal complement allows the main predicate and the dependent event to be negated as a whole, as for example in (36).

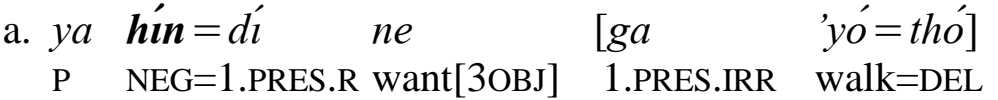
'I don't want to walk.' (Lit. 'I don’t want it I will walk.') (Txt)
$\begin{array}{llll}\text { b. } y a & h^{\prime} \boldsymbol{i m}=b i & h\langle y\rangle \text { eg- } i & {[b i=m a]} \\ \mathrm{P} & \mathrm{NEG}=3 . \mathrm{PST} & \langle\mathrm{SS}\rangle \text { let[3OBJ]-F } & \text { 3.PST=SS/go }\end{array}$
'She didn’t let him go.' (Lit. 'She didn’t let him he went.') (Txt)

\subsection{Structural complexity and finiteness}

SIT Otomi is a language with flexible SVO order. A matrix clause has up to six syntactic positions available to the left of the VP before the subject NP (for more details see Palancar 2009). These positions include: TAM markers, a number of intensives and indefinite pronouns, the marking of negation, a number of topicalized constituents like adverbials and other argumental Ss. Example (37a) illustrates the use of the intensive clitic $x a$ and the adverb $y a$. Example (37b) shows a topicalized adverbial, and (37c) a topicalized NP. 
(37)

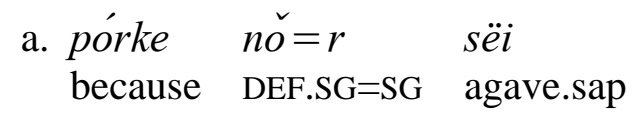

ya $\boldsymbol{x} \boldsymbol{a}=x i=z a^{\prime} t^{\prime}-i$

$\mathrm{P} \quad \mathrm{INT}=\mathrm{PERF}=\mathrm{SS} /$ thicken$[$ 3OBJ $]-\mathrm{F}$

$\tilde{r} a ́-\tilde{n}-h o$

[PRES]INT-ST-be.good[3OBJ]

'Because the pulque has already thickened alright.' (Txt)

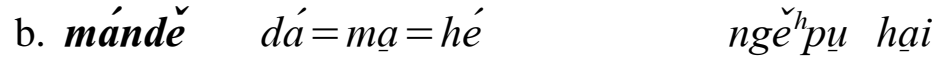

yesterday 1.PST=SS/go.PL=PL.EXCL there down

'Yesterday we went down there.' (Txt)

с. $y \boldsymbol{a}$ jǒ $\quad n-d \grave{\imath}=j \check{o}=h e ́$

PL mushroom IMPF-1.PRES.R $=$ collect $[$ ЗOBJ $]=$ PL.EXCL

há ya t'oho

LOC.P PL mountain

'We used to collect the mushrooms in the wild.' (Txt)

In contrast to matrix clauses like those in (37), the juxtaposed dependent clause can only be marked for TAM and subject agreement. This suggests that it is a truncated clause with the reduced syntax of an I node, as represented in Figure 1.

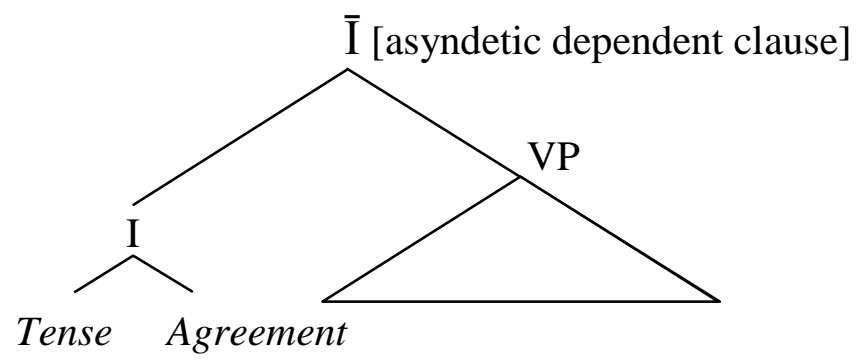

Figure 1. Structure of the asyndetic dependent clause.

The structural poverty of the Otomi asyndetic dependent clause was already mentioned in Section 3.2, where the restriction concerning negation was pointed out. It may be further illustrated with (38) and (39) by comparing the ungrammatical (b)-examples with the felicitous examples of matrix clauses in (37) above.

a. $g a=h o ' s=e ́$

1.PRES.IRR=boil[3OBJ].AS=PL.EXCL

$[d a=d \ddot{o}$ $x i=\tilde{n}-h o]$

PRES.IRR=get.cooked[3OBJ] PERF.R=ST-be.good[3OBJ]

'We boil it so that it cooks alright.' (Txt) 
b. *ga ${ }^{*} h o ' s=e ́$

1.PRES.IRR=boil[3OBJ].A=PL.EXCL

$$
\begin{aligned}
& {\left[\begin{array}{ll}
\boldsymbol{y} \boldsymbol{a} & \boldsymbol{x} \boldsymbol{a}=d a=d \check{o} \quad x i=\tilde{n}-h o]
\end{array}\right.} \\
& \mathrm{P} \quad \mathrm{INT}=\text { PRES.IRR=get.cooked[3OBJ] PERF.R=ST-be.good[3OBJ] }
\end{aligned}
$$

(39)
a. $m i=k a d-i$
$[m i=h \check{o} m-b=y a ́$
bojö]
3.IMPF. $\mathrm{R}=$ deceive[3OBJ]-F 3.IMPF.R=take.AS-3DAT=PL.3POSS money
'He used to deceive them in order to rob them of their money.' (Txt)
b. ${ }^{*} m \imath=k a d-i$
[yá bojö mín höm-b-i]
3.IMPF. $R=$ deceive[3OBJ]-F PL.3POSS money 3.IMPF. $R=$ take.AS-3DAT-F
Intended reading: like (39a)

In clear contrast to juxtaposed dependent clauses, syndetic dependent clauses in Otomi are full CPs that may have constituents filling syntactic positions to the left of the predicate, just like a matrix clause. Their structure is represented in Figure 2.

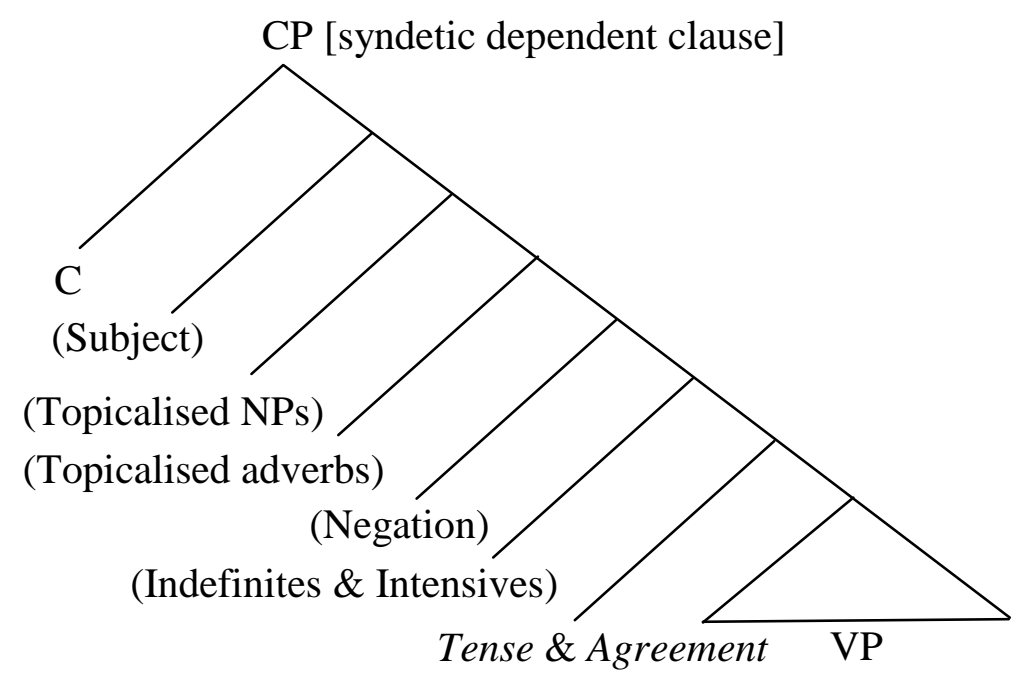

Figure 2. Structure of the syndetic dependent clause.

The structure of CPs is illustrated in (40) with fronted adverbials in a syndetic purpose clause headed by $p a ́$ and in (41) with a fronted NP in a complement clause headed by the complementizer $g e$ (which may be elided). ${ }^{12}$
a. ntǒnse $d a=g \underline{u} n g-a=k a ́$
jüni
then 3.PRES.IRR=SS/grind. $A[3 O B J]-B=L O C . P \quad$ flat.stone
[pá $\left.\quad \boldsymbol{y a} \quad d a=k^{\prime} e^{\prime} t^{\prime}-i\right]$
PURP P 3.PRES.IRR=grind.corn[3OBJ]-F

'So one grinds it on the flat stone so that now one may crumble it.' (Txt) 


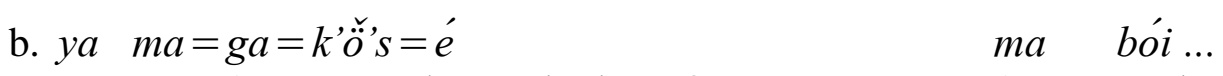

$\mathrm{P} \quad \mathrm{IMM}=1 . \mathrm{PRES} . \mathrm{IRR}=$ have.a.look.AS[3OBJ]=PL.EXCL 1POSS cattle

[pá xí_ndè ga $=$ münts $=e ́$

PURP in.the.afternoon 1.PRES.IRR=gather.AS[3OBJ]=PL.EXCL

má n’àgi]

other one_time

'We'd go and have a look at the cattle ... so that in the afternoon we'd gather it again.' (Txt)

(41)

$\begin{array}{lll}n o=r & \text { 'béhñö } & \text { pöd }-i \\ \text { DEF.SG=SG } & \text { woman } & \text { [3.PRES.R]=know[3OBJ]-F }\end{array}$

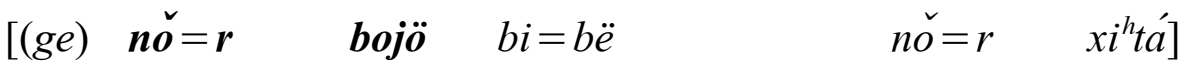

C DEF.SG=SG money 3.PST=SS/steal[3OBJ] DEF.SG=SG old.man

'The woman knows that the man stole the money.'

(Lit. ' ... that the money the man stole.')

The reduced syntax of juxtaposed dependent clauses strongly suggests that these clauses are less finite than syndetic clauses. Alternatively, the facts open up the possibility for an analysis to treat them as non-finite clauses. As Otomi languages do NOT have non-finite verb forms, the juxtaposed dependent clause serves as the functional equivalent of deranked structures such as converbs or infinitives in other languages. However, an asyndetic dependent clause also shows a number of differences from gerunds or infinitives which may also justify its treatment as a different structure. The juxtaposed clause in Otomi is marked for TAM, so that assignment of this semantic value has a correlation in the configuration of the clause, especially when it functions as an adjunct (cf. [23] and [24]). It is also marked for subject agreement. ${ }^{13}$ Furthermore, the clause is not embedded within the main clause with the external syntax of an NP, which is otherwise common with gerunds across languages, and to a certain extent with infinitives too. Moreover, when it is used as a complement clause, it does not occupy the structural slot of an argument, as for example in Turkish in (42), (adapted from Kornfilt 2007: 311).

\footnotetext{
biz $\quad[$ sinav-l geç-ti-k $] \quad$ san-lyor-uz

we test-ACC pass-PST-1PL believe-PRES.PROG-1PL

'We believe we passed the test.'
}

In (42), the dependent clause bearing both tense and agreement is embedded in the O position, as Turkish is an SOV language, and this indicates that the dependent clause is not juxtaposed. Since SIT Otomi is SVO, it could be argued that an asyndetic clause such as (43) functioning as object argument could in principle also occupy the position of O. However, there is some evidence against such an analysis. Object Ss can be topicalized, as shown in (41) above, or can be clefted as in (44). This can never happen with asyndetic dependent clauses as shown by the ungrammaticality of (45). Likewise, a dependent clause functioning as subject cannot occur before the verb, compare (46a) with (46b).

$$
\begin{aligned}
& \text { bi=ne } \quad[d a=m a] \\
& \text { 3.PST=want[3OBJ] 3.PRES.IRR=SS/go } \\
& \text { 'He wanted to go.' }
\end{aligned}
$$


(44)

gó gé=r bojö nó $b i=b \ddot{e}=$ 'á

FOC IDEN.REL $=S G$ money REL 3.PST.R $=S S /$ steal[3OBJ] $=3$

'It was the money what he stole.'

(45)
a. $*[d a=m a] \quad b i=n e$
3.PRES.IRR=SS/go 3.PST=want[3OBJ]
Intended reading: 'To go, he wanted.'
b. *gó gé $[d a=m a] \quad n o ́ \quad b i=n e=$ 'á
FOC IDEN.REL 3.PRES.IRR=SS/go REL 3.PST=want[3OBJ]=3SG
Intended reading: 'It was to go what he wanted.'

(46)
a. $m \dot{\imath}=t s \underline{a}=\left[\begin{array}{ll}g a & m a\end{array}\right]$
3.IMPF.R=be.possible=1.PRES.IRR SS/go
'I could go.' (Lit. 'It was possible that I would go.')
b. $*[g a=m a] \quad m i ́=t s a$
1.PRES.IRR=SS/go 3.IMPF.R=be.possible
Intended reading: 'That I would go was possible.'

In the light of these arguments, the asyndetic dependent clause in examples like (43) is a tensed clause which is syntactically juxtaposed to the main one at a surface level, while embedded (hence dependent) at a structural level. In contrast, infinitival or gerundive clauses, while functionally equivalent to the Otomi construction and possibly as similarly embedded in structural terms, cannot be taken to be juxtaposed in the same sense.

\subsection{Inherent control}

The notion of "inherent control" in Stiebels (2007) proves useful for an understanding of another important syntactic property of the juxtaposed construction. According to Stiebels, this type of control is found when the predicate of a main clause requires the predicate of the dependent clause to have a co-referential argument, independently of the syntactic realization of the subordinate clause. ${ }^{14}$ In the juxtaposed construction, the restriction is as follows: The subject argument of the juxtaposed clause must be co-referential with one of the arguments of the main clause. For example, as in typical purpose clauses, both the main and the goal event can share the same actor, encoded as subject (SUB) in both clauses, as in (47). ${ }^{15}$

SUB $=[\mathrm{SUB}]$

a. 'né $\boldsymbol{g a}_{i}=h \check{o ̈ x}=\dot{e}$

and 1.PRES.IRR $=$ take.AS[3OBJ] $=$ PL.EXCL

$\left[\mathrm{ga}_{i}=p \underline{a}=h e^{\prime}=y^{\prime}{ }^{\prime}\right]$

1.PRES.IRR $=$ Sell[3OBJ] $=$ PL.EXCL $=\mathrm{P}$

'And we take it to sell it.' (Txt) 

b. $\boldsymbol{b i} \boldsymbol{i}_{i}=$ 'bat'-i
$\left[\boldsymbol{b} \boldsymbol{i}_{\boldsymbol{i}}=k^{\prime}{ }^{\prime} \boldsymbol{o ́}^{\prime} t^{\prime}-i\right]$
3.PST=turn.around-F 3.PST=look.at[3OBJ]-F
'He turned around to look at it.'

The referent of the subject within the purpose clause may function as direct (DO) or indirect object (IO) of the main clause, as illustrated in (48a) and (48b), respectively:

$$
\begin{aligned}
& \text { ya gă'thó } b i=g \ddot{u}_{i}-i, \quad g \check{a} \text { thó } n u ́=y a \text { jö'i }
\end{aligned}
$$

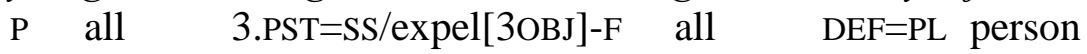

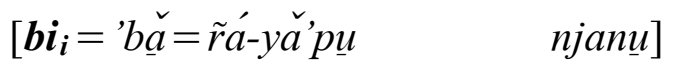

$$
\begin{aligned}
& \text { 3.PST=stand.B=INT-far.away that.way }
\end{aligned}
$$

b. $\mathrm{IO}=[\mathrm{SUB}]$

$$
\begin{aligned}
& \text { 'né... ga } g \text { 'úm-p } \boldsymbol{p}_{i}=\text { hé n'à txí-tui } \\
& \text { and 1.PRES.IRR=give.to.3.AS-3DAT=PL.EXCL one DIM-bit } \\
& {\left[d a_{i}=h\langle\tilde{n}\rangle \text { öts' }-i\right]} \\
& \text { 3.PRES.IRR }=\langle\text { SS } ` \text { take[3OBJ]-F } \\
& \text { 'And we give them a little bit to take home.' (Txt) }
\end{aligned}
$$

The juxtaposed construction CANNOT however be used when the subject of the dependent clause is not co-referential with an argument of the predicate of the main clause, as shown by the ungrammaticality of (49) (with a purposive interpretation):

$$
\begin{aligned}
& \text { a. }{ }^{*} \boldsymbol{d} \boldsymbol{a}_{i}=n a ́ n g-i \quad\left[\boldsymbol{g} \boldsymbol{i}_{j}=h\langle\tilde{n}) \ddot{u} d-i\right] \\
& \text { 1.PST=get.up-F 2.PRES.IRR=〈SS }>\text { sit.down-F } \\
& \text { Intended reading: 'I stood up for you to sit down.' }
\end{aligned}
$$

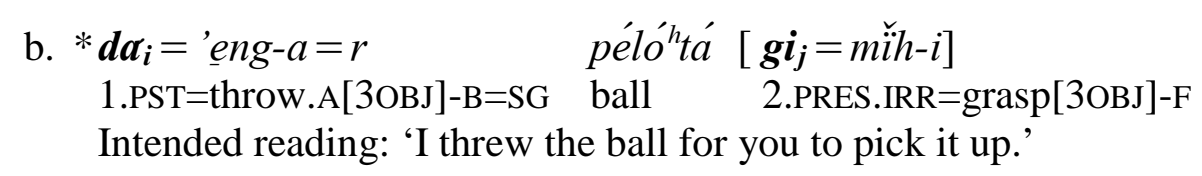

In order to convey such readings, SIT Otomi uses alternative syndetic dependent clauses, for example in (50a-b) (with a purposive reading), clause or in (50c) (with a complement clause).

$$
\begin{aligned}
& \text { a. } \operatorname{SUB} \neq[\mathrm{SUB}] \\
& d a_{i}=\text { náng- } i \\
& \text { 3.PRES.IRR=get.up- } \mathrm{F} \\
& \boldsymbol{d} \boldsymbol{a}_{i}=h\langle y\rangle o^{h} k-w-\dot{a}=r \quad t x i^{h} t x i \\
& \text { 3.PRES.IRR }=\langle\text { SS }>\text { make-3DAT-B.3POSS=SG baby's.bottle } \\
& {\left[\begin{array}{ll}
p a ́ & d a_{j}=z i
\end{array}\right]} \\
& \text { PURP 3.PRES.IRR=SS/ingest[3OBJ] } \\
& \text { 'She gets up to prepare him (the baby) his bottle so that he drinks it.' (Txt) }
\end{aligned}
$$


b. $\mathrm{DO} \neq[\mathrm{SUB}]$

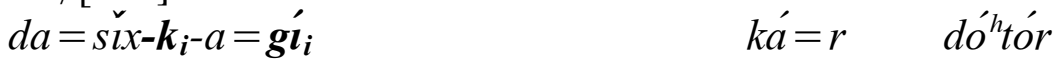

$$
\begin{aligned}
& \text { 3.PRES.IRR=IS/take.animate-1OBJ-B=1OBJ LOC.P=SG doctor } \\
& \text { [pá } \left.\quad \boldsymbol{d a}_{\boldsymbol{j}}=\text { 'othe }=\text { gí }\right] \\
& \text { PURP 3.PRES.IRR=heal }=1 \text { OBJ }
\end{aligned}
$$

c. $\mathrm{IO} \neq[\mathrm{SUB}]$

$$
\begin{aligned}
& d a^{\prime}=\underline{a}^{h}-\boldsymbol{p}_{\boldsymbol{i}}-a=\boldsymbol{b}_{\boldsymbol{i}} \quad\left[(g e) \boldsymbol{g} \boldsymbol{i}_{\boldsymbol{j}}=m a\right] \\
& \text { 1.PST=ask.for.A-3DAT-B=3DAT C 2.PRES.IRR=SS/go } \\
& \text { 'I asked him that you would go.' }
\end{aligned}
$$

Such constructions are control-neutral, that is, they can also be used when there is argument coreference between the clauses, as for example in (51).

$$
\begin{aligned}
& \mathrm{SUBJ}=[\mathrm{SUBJ}] \\
& \text { i } \quad \text { asi } \quad \boldsymbol{d}_{\boldsymbol{i}}=j a \check{a}=p \underline{u} \quad\left[p a ́ \quad g \boldsymbol{a}_{\boldsymbol{i}}=p \underline{a}\right] \\
& \text { and so 1.PRES.R }=\mathrm{do}[3 \mathrm{OBJ}]=\text { like.that PURP 1.PRES.IRR=sell[3OBJ] } \\
& \text { 'And I do it so to sell them.' (Txt) }
\end{aligned}
$$

\subsection{Summary of properties}

A summary of the grammatical properties exhibited by dependent clauses in the juxtaposed construction of Otomi is provided in Table 4. These properties are compared to those of dependent clauses headed by conjunctions. The asymmetries surveyed in Table 4 indicate that the asyndetic dependent clause in Otomi is a deranked syntactic structure.

\begin{tabular}{ll|l} 
& Asyndetic dependent clause & Syndetic dependent clause \\
\hline Intonation & One single unit with the main clause & Independent unit \\
TAM & Dependent and restricted & Independent \\
Negation & Cannot be negated & Can be negated \\
Complexity & Reduced structure: an $\overline{\mathrm{I}}$ & Full structure: a CP \\
Control & $\begin{array}{l}\text { Inherent: Co-referential argument is } \\
\text { realized as subject }\end{array}$ & Control-neutral \\
\hline
\end{tabular}

Table 4. Properties of the two types of dependent clauses.

\section{Syntactic integration}

The juxtaposed construction at times surfaces as a grammatical structure which shows a high degree of syntactic integration between the main and the dependent clause. This phenomenon may be seen in two domains: (i) in the marking of a plural subject; and (ii) in a special morphological adjustment I call ‘compaction’ that verbs in the main clause may undergo. 


\subsection{Plural marking}

In Otomi, a clause with a first or second person plural subject is obligatorily marked by means of a number enclitic. This enclitic is commonly hosted by the verbal predicate, as in (52a-c).
a. $g a=p \underline{a}=\boldsymbol{h} \dot{e}$
'na $=r$
$t^{\prime \prime}-t \underline{u}^{h} k d o$

1.PRES.IRR=sell[3OBJ]=PL.EXCL IND.SG=SG DIM-female.turkey

'We sell a turkey.'

b. $g a=h o \tilde{n}=\boldsymbol{h} \boldsymbol{e}$

1.PRES.IRR=look.for[3OBJ].A=PL.EXCL

tó $\quad \varnothing \quad d a=\max -k=\boldsymbol{h} \dot{e}=$ 'né

someone REL 3.PRES.IRR=SS/help.A-1OBJ=PL.EXCL=also

'We look for whom may help us.'

The number enclitic may alternatively be hosted by an NP having a plural possessor that is coreferential with the subject, as in (53):

$$
\begin{array}{ll}
\text { komo } & h \ddot{\imath}={ }^{\prime} o_{-} t h o ́ \\
\text { as } & \text { NEG }=[3 . P R E S] \text { not.exist_DEL } \\
\text { té } & \varnothing \quad \boldsymbol{g a}_{\boldsymbol{i}}=t s i^{h}-p-a=\left[\boldsymbol{m a}_{\boldsymbol{i}} \quad h m \check{e}=\boldsymbol{h} \dot{\boldsymbol{e}}_{\boldsymbol{i}}\right]_{\mathrm{NP}}
\end{array}
$$

something REL 1.PRES.IRR=ingest-3DAT-B=1POSS tortilla=PL.EXCL

'As there wasn't anything with which we could eat our tortillas.' (Txt)

(Lit. ' ... with which I could eat our tortillas.')

This coding pattern also applies to many instances of the juxtaposed construction, as shown in (54), where plural marking appears in each clause.

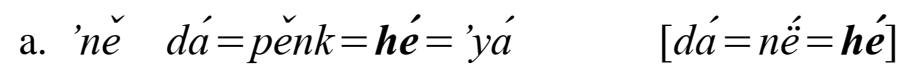
and 1.PST=return.AS=PL.EXCL $=\mathrm{P}$ 1.PST $=$ dance. $A S=P L . E X C L$

'And we returned to dance.' (Txt)
b. $d a^{\prime}=j w a ́=h e ́$
1.PST=finish.AS[3OBJ $]=$ PL.EXCL $\quad 1 . P S T=$ dance. $. A S=P L . E X C L$

'We finished dancing.' (Txt)

However, when there is subject co-reference between the main and the dependent clause in the juxtaposed construction, the plural enclitic can alternatively be hosted by the juxtaposed clause ONLY, as illustrated in (55a-b) for purpose clauses and in (56) for a complement clause.
a. $d \dot{a}=n \check{n} n g-i \quad[d a ́=n \ddot{e}=\boldsymbol{h e}]$ 1.PST=get.up- $\mathrm{F} \quad 1 . \mathrm{PST}=$ dance. $\mathrm{AS}=\mathrm{PL} . \mathrm{EXCL}$
'We got up to dance.' (Txt)
(Lit. 'I got up we danced.') 
b. $g a=$ pěng- $i$
1.PRES.IRR=return-F
[ga $\mathrm{g}$ pét $=\boldsymbol{h} \boldsymbol{e}$
ya hmě = 'yá]
1.PRES.IRR $=$ smash.AS[3OBJ] $=$ PL.EXCL PL tortilla $=\mathrm{P}$
'We return to make the tortillas.' (Txt)
(Lit. 'I'd return we'd make tortillas.')

(56) kwándo dí=ne

when 1.PRES.R=want[3ОВJ]

$\left[g a=h o^{\natural} k-a=n ' \check{a} \quad\right.$ ma tráhé=hé $]$

1.PRES.IRR $=$ make- $\mathrm{B}=$ one 1 POSS dress $=$ PL.EXCL

'When we want to make our dresses.' (Txt)

(Lit. 'When I want I'd make one (of) our dress.')

In the juxtaposed construction, it is the main clause that drops grammatical marking; not the dependent one. If the enclitic were elided in the second clause, the structure would be interpreted as a sequence of two paratactically aligned matrix clauses, as in example (57). Note that the purpose reading is not possible.

$$
\begin{aligned}
& {[d a ́=n a ́ n k=\boldsymbol{h e}](\#) \quad[d a ́=n \ddot{e}-i]} \\
& \text { 1.PST=get.up.AS=PL.EXCL 1.PST }=\text { dance-F }
\end{aligned}
$$

a. 'We got up (and) I danced.'

b. *'We got up to dance.'

\section{2. "Compaction" of the main verb}

Verbs in Otomi languages commonly show a morphological contrast conditioned by the verb's sensitivity to its syntactic environment. This contrast is known as "compaction". When a verb shows compaction it may appear in two inflectional shapes: a "free shape" (F-shape), illustrated in (58), and a "bound shape" (B-shape), shown in (59). The free shape is a pausal form which is used before a clausal and/or a prosodic boundary. The bound shape is a cliticized form, which is employed when the verb occurs intraclausally (for more details see Palancar 2004, 2011).

(58) F-shape

a. $\left[b i=y \underline{u} t^{\prime}-\boldsymbol{i}\right] \#$

3.PST=SS/get.in-F

'He got in.' (Txt)

b. ['ně $b a ́=$ 'ёh-ë] \#

and 3.HITHER.PST=come-F

'She came back.' (Txt) 
(59) B-shape

$\begin{array}{ll}\text { a. }\left[b i=y \underline{u} t^{\prime}-a=(' n a=r\right. & \left.n d \underline{o})_{\mathrm{NP}}\right] \# \\ \text { 3.PST=SS/get.in-B=IND.SG=SG } & \text { man }\end{array}$

'A man got in.' (Txt)

(Lit. 'Got in a man.')

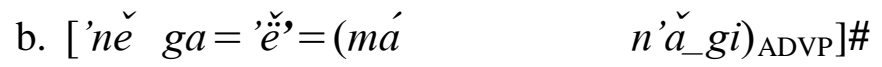

and 1.PRES.IRR $=$ come. $\mathrm{B}=$ other one_time

'And she came again.' (Txt)

In the juxtaposed construction, as shown in (60), the verb in the main clause appears in F-shape because it occurs at the clausal boundary before the dependent clause. This behaviour is expected of all verbs occurring at clausal boundaries, and it may be seen as well in juxtaposed clauses which are paratactically linked, as in (61).
a. $d a=d \ddot{o} t '-i \quad[d a=g o ' m-i]$
3.PRES.IRR=SS/tie[3OBJ]-F 3.PRES.IRR=SS/cover[3OBJ $]-\mathrm{F}$
'They'd tie it to cover it up.' (Txt)
b. ya kwándo gi=jwád-i [gi=tsi
$\mathrm{P}$ when 2.PRES.IRR=finish[3OBJ]-F 2.PRES.IRR=ingest[3OBJ]
ri désáyúnó]
2POss breakfast
'When you'd finish eating your breakfast.' (Txt)

(61)
$[$ bi $=$ zón-i $] \#$
$\left[b i=\tilde{n} \ddot{u}{ }^{\prime} t s^{\prime}-a=n \check{o}=r\right.$
xóni]
3.PST=SS/arrive.there-F 3.PST=fill[3OBJ]-B=DEF.SG=SG pitcher
'She arrived and filled her water jug.' (Txt)

F-shapes and B-shapes are NOT interchangeable. When a B-shpe is used in the syntactic context where an F-shape is expected, the result is normally ungrammatical, as shown in (62a) (but see the examples in [63] below). The same is true for an F-shape used in the context of a B-shape, as shown in (62b).

a. B-shape in the context of a F-shape

$$
\begin{array}{ll}
* d a^{\prime}=j w a^{h} t-a=\left[d a^{\prime}\right. & \left.h o^{h} k-i\right] \\
\text { 1.PST=finish[3OBJ]-B=1.PST } & \text { make[3OBJ]-F } \\
\text { Intended reading: 'I finished doing it.' }
\end{array}
$$

b. F-shape in the context of a B-shape

$$
\begin{aligned}
& * d a^{\prime}=j w a^{h} t-i \quad g a^{\prime} t h o \\
& 1 . P S T=\text { finish[3ОВJ]-F all } \\
& \text { Intended reading: 'I finished everything.' }
\end{aligned}
$$


Interestingly, despite the ungrammaticality of (62a), a number of verbs in the main clause may also appear in B-shape before the asyndetic dependent clause. When this happens, the verb serves as a host for the TAM clitics of the dependent clause. The phenomenon is illustrated in (63).

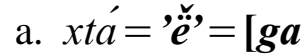
$t s i x-i=r i$
jödö]
1.PERF. $\mathrm{R}=$ come. $\mathrm{B}=1 . \mathrm{PRES} . \mathrm{IRR}$ take.animate.AS[3OBJ]-B=2POSS brother.of.man
'I've come to take your brother.' (Txt)

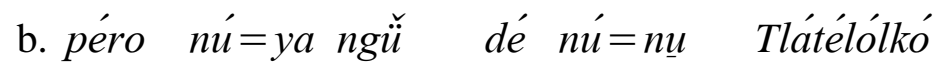

but $\mathrm{DEF}=\mathrm{PL}$ house of $\mathrm{DEF}=$ there Tlatelolco

$b i=t h e^{\check{\prime}}=[\boldsymbol{b i} \quad$ yót'-e $]$

3.PST=affect.completely.B=3.PST collapse.mass-F

'But the houses in Tlatelolco collapsed completely.' (Txt)

The use of compaction in examples like (63) indicates the disappearance of the syntactic boundary between the main and the dependent clause as motivated by a growing degree of syntactic integration. The main verbs that undergo compaction are given in Table 5.

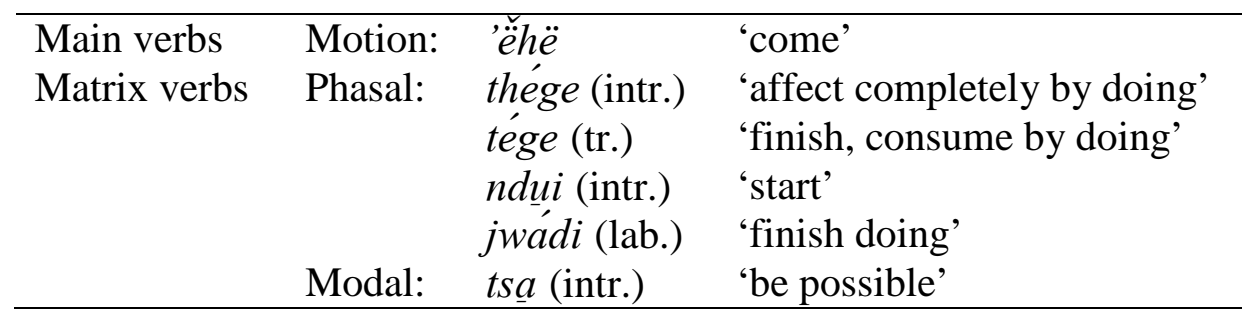

Table 5. Verbs allowing compaction in the juxtaposed construction.

The modal verb $t s \underline{a}$ 'be possible' does not have a B-form per se. Because of this, this verb does not undergo compaction in the strict sense, but it behaves in a similar fashion as the other main verbs in Table 5 because it hosts the TAM clitic of the dependent clause. This is shown in (64):
ge $\quad h \imath^{\prime}=m i$
$t s \underline{a}=[n-d a$
' $\tilde{n} \ddot{o} \tilde{n}]={ }^{\prime} \ddot{a}$
IDEN.REL NEG=3.IMPF.R be.possible=IMPF-3.PRES.IRR move.AS=3SG
'That (his tongue) was what he couldn't move.' (Txt)
(Lit. 'That was what it was impossible for him to move.')

Finally, when a verb from Table 5 is used in the B-shape and the clause has a plural subject in the first or second person, the number enclitic can only occur in the dependent clause, as shown in (65).

$$
\begin{aligned}
& d a^{\prime}=n d \underline{u^{\prime}}=\left[d a^{\prime} \quad z o_{\tilde{n}}=\boldsymbol{h} \underline{u}\right] \\
& \text { 1.PST }=\text { start.B=1.PST weep.AS=PL(.INCL) } \\
& \text { 'We started crying.' }
\end{aligned}
$$




\section{Conclusions}

In this paper, I have claimed that clausal juxtaposition is a clause combining mechanism which can be used to convey both hypotactic and paratactic relations between the clauses involved. The case is shown with a construction in Otomi which consists of a main clause and a juxtaposed dependent clause. Such a dependent clause may function as an adjunct of the main predicate or as a clausal complement of specific complement-taking verbs. When it functions as an adjunct, it commonly conveys purposive semantics, though simultaneous readings are also possible. I have also shown that this dependent juxtaposed clause, though finite, is a deranked structure which is functionally and structurally equivalent to other deranked structures like infinitives or gerundives in other languages.

I have pointed out that finding clause juxtaposition being used as a productive clause combining mechanism in a given language does NOT entail that the clauses involved necessarily stand in a paratactic relation to each other. In those cases where a hypotactic relation between the juxtaposed clauses is indicated by the use of unitary prosody, the Otomi case shows that this fact does NOT entail that the dependent clause has a syntactic structure equivalent to that of a matrix clause, for it may covertly present the same morphosyntactic hallmarks that formally characterize dependent clauses in other languages.

Besides, the juxtaposed dependent clause in Otomi is not an instance of coordination because it does not obey the coordinate structure constraint of Ross (1967), as elements in its structure can be extracted for questioning, focus or relativization (see example [66]).

$$
\text { ¿tó go nó gínene }\left[g i=n u_{-}\right] \text {? }
$$

someone FOC REL 2.PRES.R=want[3OBJ] 2.PRES.IRR=see[3OBJ]

'Whom do you want to see?' (Lit. 'Who is it that you want to see?')

On the other hand, the juxtaposed construction of Otomi presented in this article is no doubt typologically related to other constructions in the world's languages which also use juxtaposition as a grammatical device to encode dependent inter-clausal relations. However, at least in the better known cases reported so far the languages in question commonly have predicate or verbal, rather than clausal, juxtaposition. For example, in bona fide serial verb constructions, as characterized in Aikhenvald (2006), a sequence of verbs jointly acts as a single predicate in one clause. ${ }^{16}$ In other cases, we seem to have a sequence of predicates rather than of verbs, as for example in Tzotzil (Mayan), where there is a serial predicate construction identified in the literature (Haviland 1981, 1993; Gast 1998) which is used to express purpose and consequence. ${ }^{17}$ This construction consists of two juxtaposed predicates marked for person, but only the first predicate is marked for aspect while the second one is marked for the so-called 'subjunctive' mood, a dependent mood. An example is given in (67), (Haviland 1993: 35, apud Gast 1998: 76).

$$
\begin{aligned}
& \text { ch-i-muy j-tuch'- } \boldsymbol{-}-\varnothing \quad \text { i } \quad \text { tajchuch }=e \\
& \text { IND/ICP-1ABS-climb 1ERG-Cut-SUBJ-3ABS DET mushroom=CL } \\
& \text { 'I climbed up to pick the lentinus mushroom.' }
\end{aligned}
$$

The Tzotzil construction represents an intermediate stage between a proper serial verb construction and the clausal juxtaposition construction presented for languages like Otomi, which 
consists of two clauses with predicates marked for TAM and subject agreement. Such structural similarities suggest the existence of a cline for the emergence of complex predication and auxiliarization, which has been proposed in different forms (for example DeLancey 1991; Givón 1991, 2009, etc.) and has been revisited by Anderson (2005: 4), as shown in (68), (stage [f] is adapted from "univerbated suffix” into "affix”).

(a) parataxis > (b) hypotaxis > (c) serialisation > (d) light verb > (e) auxiliary > (f) affix

While the linearity of such a cline has been criticized by Bowern (2008) as too simplistic, especially regarding the emergence of light verbs from serialisation, the literature is more in agreement about stage (a) > (b). However, it should be noted that parataxis and hypotaxis represent two fundamental types of clausal relations inherent to all kinds of clause combining devices, but are not grammatical constructions per se, like the other stages of the cline. Therefore, they should not be placed at the same level as the other stages in clines such as (68). Moreover, stage (a) > (b) is based on the general identification of clausal juxtaposition with parataxis as an encoder of asyndetic coordination. I hope to have shown in this paper that the three concepts parataxis and hypotaxis, on the one hand, and clausal juxtaposition, on the other - should be taken to be distinct categories, and in this light, I propose an amendment of the cline in (68) as shown in (69).

(69) (a) clausal juxtaposition > (b) serialisation > (c) light verb > (d) auxiliary > (e) affix (paratactic > hypotactic)

In the cline in (69), clausal juxtaposition is given its right place as a grammatical device. It is typologically expected that if a language uses juxtaposition to encode hypotactic relations, it will also use it both productively and extensively to express paratactic relations between clauses. When used for this purpose, juxtaposition commonly renders a sequential and/or consequential reading between the events expressed in the clauses involved. It should be borne in mind, however, that such readings are not quintessential to clausal juxtaposition as a grammatical device per se, as is often assumed, but only to clausal juxtaposition when it is used to encode parataxis.

The Oto-Manguean case presented here with Otomi raises important questions, both for a general theory of language and for typological methodology, as instances of subordination encoded by clausal juxtaposition in other languages may conceal similarly complex underlying structures which are not apparent from surface phenomena. 


\section{References}

Aarts, Bas. 2006. Subordination, in Keith Brown (ed.), The Encyclopedia of Language and Linguistics Vol. 5 (Second edition), 248-254. Elsevier.

Aikhenvald, Alexandra Y. 2006. Serial verb constructions in typological perspective, in Alexandra Y. Aikhenvald (ed.), Serial Verb Constructions: A Cross-Linguistic Typology, 1-68. Cambridge: Cambridge University Press.

Anderson, Gregory. 2005. Auxiliary Verb Constructions. Oxford: Oxford University Press.

Bartholomew, Doris. 1973. Otomi dependent clauses, in C. Corum, Thomas C. Smith-Stark and A. Weiser (eds.), You Take the High Node and I'll Take the Low Node. Chicago Linguistics Society 7, 1-8.

Bowern, Claire. 2008. The diachrony of complex predicates. Diachronica 25:2, 161-185.

Comrie, Bernard. 2008. Subordination, coordination: Form, semantics, pragmatics, in Edward Vajda (ed.), Subordination and coordination strategies in North Asian languages, 1-16. Amsterdam: John Benjamins.

Cosme, Christelle. 2006. Clause combining across languages: A corpus-based study of EnglishFrench translation shifts. Languages in Contrast 6:1, 71-108.

Cristofaro, Sonia. 2003. Subordination. Oxford: Oxford University Press.

Cristofaro, Sonia. 2005. Purpose Clauses (Chapter 125), in Martin Haspelmath, Matthew S. Dryer, Hans-Jorg Bibiko, David Gil, Bernard Comrie and Claudia Schmidt (eds.), World Atlas of Language Structures, 506-09. Oxford: Oxford University Press. Accessible at $<$ http://wals.info/feature/description/125>.

Culicover, Peter and Ray Jackendoff. 1997. Semantic subordination despite syntactic coordination. Linguistic Inquiry 28:2, 195-218.

Deane, Paul. 1992. Grammar in mind and brain: Explorations in cognitive syntax. New York: Mouton de Gruyter.

DeLancey, Scott. 1991. The origins of verb serialization in Modern Tibetan. Studies in Language 15:1, 1-24.

Dixon, R.M.W. 1995. Complement clauses and complementation strategies, in F. Palmer (ed.), Grammar and Meaning: Essays in honor of Sir John Lyons, 175-220. Cambridge: Cambridge University Press.

Dixon, R.M.W. 2006. Complementation Clauses and Complementation Strategies in Typological Perspective, in R.M.W. Dixon and Alexandra Y. Aikhenvald (eds.), Complementation: A Cross-Linguistic Typology, 1-48. Oxford: Oxford University Press. 
Gast, Volker. 1998. On Clause Combining in Tzotzil. Unpublished MA Dissertation at Johannes Gutenberg-Universität Mainz.

Givón, Talmy. 1990. Syntax: A functional-typological introduction, Vol. II. Amsterdam: John Benjamins.

Givón, Talmy. 1991. The evolution of dependent clause morpho-syntax in Biblical Hebrew, in Elizabeth C. Traugott and Bernd Heine (eds.), Approaches to Grammaticalization, Vol. 2: Focus on Types of Grammatical Markers, 257-310. Amsterdam: John Benjamins.

Givón, Talmy. 2009. The Genesis of Syntactic Complexity. Amsterdam: John Benjamins.

Haiman, John. 1985. Natural syntax: Iconicity and erosion. Cambridge: Cambridge University Press.

Halliday, M.A.K. 1985. An Introduction to Functional Grammar. London: Edward Arnold.

Haviland, John. 1981. Sk’op Sotz’leb: El Tzotzil de San Lorenzo Zinacantan. Mexico City: Universidad Nacional Autónoma de México.

Haviland, John. 1993. The syntax of Tzotzil auxiliaries and directionals. Berkeley Linguistics Society 19, 35-49.

Hoeksema, Jacob and Donna Napoli. 1993. Paratactic and Subordinative So. Journal of Linguistics 29:2, 291-314.

Hyman, Larry. 1971. Consecutivization in Fe?fe?. Journal of African Languages 10-2: 29-43.

Johannessen, Janne Bondi. 1998. Coordination, [Oxford Studies in Comparative Syntax]. Oxford: Oxford University Press.

Kornfilt, Jaklin. 2007. Verbal and nominalized finite clauses in Turkish, in Irina Nikolaeva (ed.), Finiteness: Theoretical and Empirical Foundations, 305-332. Oxford: Oxford University Press.

Lakoff, George. 1986. Frame semantic control of the Coordinate Structure Constraint. Chicago Linguistics Society 22:2, 152-167.

Lanier, Nancy. 1968. Three structural layers in Mezquital Otomi clauses. Linguistics 43:1, 3285.

Li, Charles N. and Thompson, Sandra A. 1973. Serial Verb Constructions in Mandarin Chinese: Coordination or Subordination? Papers from the Comparative Syntax Festival, Chicago Linguistics Society 9, 96-113. 
Longacre, Robert E. 1966. Trique clause and sentence: A study in contrast, variation, and distribution. International Journal of American Linguistics 32: 242-252.

Nespor, Marina and Irene Vogel. 1986. Prosodic Phonology. Dordrecht: Foris.

Noonan, Michael. 1985. Complementation, in Timothy Shopen (ed.), Language Typology and Syntactic Description, Volume 2: Complex Constructions, 42-140. Cambridge: Cambridge University Press.

Noonan, Michael. 2006. Complement Clauses, in Keith Brown (ed.), The Encyclopedia of Language and Linguistics (Second edition). 694-697. Elsevier.

Palancar, Enrique L. $\quad$ 2004. Verbal morphology and prosody in Otomi. International Journal of American Linguistics 70:3, 251-78.

Palancar, Enrique L. 2009. Gramática y Textos del Hñöñhö: Otomí de San Ildefonso Tultepec, Querétaro, Volumen I: Gramática. Mexico City: Plaza y Valdés.

Palancar, Enrique L. 2011. Shape conditions in Otomi. Invited paper read at the III Morphology Meeting of the Southeast, University of Surrey, (8 April.)

Pride, Kitty. 1965. Chatino Syntax, [Publications in Linguistics and Related Fields 12]. Norman: University of Oklahoma, Summer Institute of Linguistics.

Quirk, Randolph, Sidney Greenbaum, Geoffrey Leech, and Jan Svartvik. 1985. A Comprehensive Grammar of the English Language. London: Longman.

Ross, John R. 1967. Constraints on variables in syntax. PhD dissertation, MIT.

Schmerling, Susan. 1975. Asymmetric conjunction and rules of conversation, in Peter Cole and Jerry L. Morgan (eds.), Syntax and semantics 3: Speech acts, 211-231. New York: Academic Press.

Stiebels, Barbara. 2007. Towards a typology of complement control, in: Barbara Stiebels (ed.), ZAS Papers in Linguistics 47, 1-80.

Thompson, Sandra A. and Robert E. Longacre. 1985. Adverbial clauses, in Timothy Shopen (ed.), Language Typology and Syntactic Description, Volume 2: Complex Constructions, 171234. Cambridge: Cambridge University Press.

Thompson, Sandra A., Robert E. Longacre and Shin Ja J. Hwang. 2007. Adverbial clauses, in Timothy Shopen (ed.), Language Typology and Syntactic Description, Volume 2: Complex Constructions [ $^{\text {nd }}$ Edition], 237-300. Cambridge: Cambridge University Press.

Wacke, O. 1931. Formenlehre der Ono-Sprache. Zeitschrift für Eingeborenen-Sprachen 21: 161-208. 


\section{Notes}

This paper was written under the auspices of the ESRC/AHRC project ES/I029621/1 "Endangered Complexity: Inflectional classes in Oto-Manguean languages". I dedicate the paper to Judith Aissen as a way to thank her for her teachings. I also want to thank Roberto Zavala, Verónica Vázquez, Gilles Polian, Paulette Levy and Sonia Cristofaro for their invaluable comments on earlier versions of this article. My sincere gratitude to the editors of this book, Volker Gast and Holger Diessel, for all their insightful observations and for their carefulness with details in editorial matters. I also want to thank the external reviewer of the book who spotted weak areas that needed attention.

Readings like these emerge when juxtaposition is used as a linking device encoding parataxis.

An analogous reading is found in the serial verb constructions of a number of languages, for example in Ono (Trans-New Guinea), where according to Wacke (1931, apud Haiman 1985: 112), juxtaposed verbs tend to render simultaneous events while coordinated VPs render sequential readings.

Hoeksema and Napoli (1993) use the term "parataxis" to refer to this intermediate level. In my opinion, the choice of the term is rather unfortunate in this context.

I use standard Otomi orthography, which deviates from the IPA in the following ways: $\left\langle\right.$ ' $>/ 2 / ;\langle f\rangle / \mathrm{p}^{\mathrm{h}} /$;

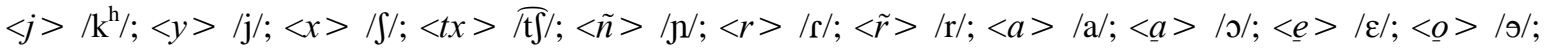
$\langle\underline{u}\rangle / \mathbf{i} /$. Umlaut indicates a nasal vowel $(<\ddot{a}>/ \tilde{a} / ;<\ddot{u}\rangle / \tilde{\mathrm{u}} /$, etc.). Otomi languages have three tones: ascending $\check{v}$; high $\dot{v}$; and low, which is not represented. Abbreviations: « non-concatenative morpheme; = clitic; _ lexicalized morpheme; AS adjusted stem; ACC accusative; ADVP adverbial phrase; ANTIP antipassive; B bound shape; C complementizer; DAT dative; DEF definite; DEL delimitative; DIM diminutive; DU dual; EMPH emphatic; EXCL exclusive; F free shape; FOC focus; IDEN indentifier; IMM immediative; IMPF imperfect; INCL inclusive; INT intensive; intr. intransitive; IRR irrealis; IS impersonal stem; lab. labile verb; LOC.ACT locative actualizer; LOC.P locative preposition; MIDD middle; NEG negation; OBJ object; P (aspectual) particle; PL plural; POSS possessive; PPERF plu-perfect; PERF perfect; PL plural; PRES present; PROG progressive; PST past; PURP purposive; QUOT quotative; R realis; REL relative; SG singular; SS secundary stem; ST stative; TAM tense/aspect/mood; tr. transitive.

The source of a textual example is indicated as (Txt). All textual examples come from a large database collected in Mexico under the auspices of the SEP-CONACyT-47175 research project.

I want to thank Eva Schultze-Berndt for making me aware of this phenomenon.

On the other hand, with syndetic constructions, having an overt marker to signal the introduction of a dependent clause does not always entail obtaining a single interpretation because conjunctions are often polysemous.

Intransitive verbs that encode their subject argument morphologically as an object inflect for TAM values by means of third person markers.

By using the irrealis the speaker does not commit him/herself to the factuality of the goal event, i.e. in the interpretation of (22), there is no semantic entailment that the woman did not bring the water, i.e. she could or could not have brought it.

Pulque is a Spanish word for a fermented drink made from maguey sap, which is a large kind of agave growing in Central Mexico.

In example (32), the fact that the goal event does not take place does not necessarily preclude the use of the past in the dependent clause. When the past is used, the goal event is presented as a presupposed expected 
goal. Using a tense of the irrealis mood, as in (i), entails either that the subject is not a drinker or that the speaker discards the idea that the act of drinking was the real reason why he didn't go.

(i) $h^{\prime} i m=b i \quad m a \quad[d a \quad n=t s i$-the $]$

NEG=3.PST sS/go 3.PRES.IRR SS=ingest-water.AS

'He didn’t go to have a drink.'

In English, the complementizer can be elided if it functions as object, like in (ii).

(ii) a. I think [that you saw someone]

b. I think [you saw someone]

The situation in (ii) raises the question of whether (iia) is the same structure as (iib) or whether they should be treated as two different types, one syndetic and the other asyndetic. A closer inspection of the behaviour of these clauses in relation to the coordinate structure constraint discussed by Ross (1967) reveals that they indeed are two different constructs. This is illustrated in (iii) and (iv), from (Comrie 2008: 8). For example, while both the structures in (ii) are subordinated, (iib) is more embedded, because both its object and subject can be extracted for relativization, as shown in (iiib) and (ivb), respectively. With type (iia), only the object can be extracted.

(iii) a. The person that I think [that you saw __ ]

b. The person that I think [you saw. ]

(iv) a. *The person that I think [that __ saw you]

b. The person that I think [ _ saw you]

In this respect, it could be argued that agreement with subject is necessary by the morphology because clitics are cummulative for TAM and subject cross-reference. However, in other instances of the grammar (mainly in patientive intransitive verbs), there is neutralization of subject in favour of a third person clitic, which works as an exponence of an empty nominative subject. In principle, nothing would preclude the ayndetic clause to receive a dummy person clitic of third person if agreement wasn't an active head in the structure.

The co-referential argument most commonly functions as a subject of the dependent clause. "Structural control" is similar to "inherent control", but in the former case the dependent clause is non-finite.

The referent of the subject of the dependent clause may be semantically included in the reference of the subject of the main clause, as in (v).
(v) náng-i $\quad[g a=m e]$ !
[IMPERATIVE]get.up-F 1.PRES.IRR=SS/go.DU
'Get up so that we may go!' (Txt)

Aikhenvald (2006: 1) defines such constructions as follows: "A serial verb construction (SVC) is a sequence of verbs which act together as a single predicate, without any overt marker of coordination, subordination, or syntactic dependency of any other sort. Serial verb constructions describe what is conceptualized as a single event. They are monoclausal; their intonational properties are the same as those of a monoverbal clause, and they have just one tense, aspect, and polarity value. SVCs may also share core and other arguments. Each component of an SVC must be able to occur on its own. Within an SVC, the individual verbs may have same, or different, transitivity values.”

The construction appears not to be productive synchronically, as it displays a number of collocational restrictions. 